\title{
Particle Crushing Effect on The Geotechnical Properties of Soil
}

\author{
Touqeer Ali Rind \\ Department of Civil Engineering, \\ Mehran University of Engineering and \\ Technology, Shaheed Zulfiqar Ali Bhutto \\ Campus, Khairpur Mirs', Pakistan \\ touqeerali@muetkhp.edu.pk
}

\author{
Hemu Karira \\ Department of Civil Engineering, \\ Mehran University of Engineering and \\ Technology, Shaheed Zulfiqar Ali Bhutto \\ Campus, Khairpur Mirs', Pakistan \\ engr.hemu07civil@gmail.com
}

\author{
Ashfaque Ahmed Jhatial \\ Department of Civil Engineering, \\ Mehran University of Engineering and \\ Technology, Shaheed Zulfiqar Ali Bhutto \\ Campus, Khairpur Mirs', Pakistan \\ ashfaqueahmed@muetkhp.edu.pk
}

\author{
Samiullah Sohu \\ Department of Civil Engineering, \\ Quaid-e-Awam University of Engineering, Science and \\ Technology, Larkana Campus, Larkana, Sindh, Pakistan \\ engr.samiullah@quest.edu.pk
}

\author{
Abdul Razzaque Sandhu \\ Department of Civil Engineering, \\ Mehran University of Engineering and Technology, Shaheed \\ Zulfiqar Ali Bhutto Campus, Khairpur Mirs', Pakistan \\ abdulrazzaque@muetkhp.edu.pk
}

\begin{abstract}
Foundations are considered as the backbone of a structure. Most of the times, the foundation is laid on the soil. For the foundation design of any structure, we need to know beforehand the soil conditions such as shear strength and permeability. These parameters help us determine the bearing capacity of the soil. The soil conditions are determined by performing various laboratory tests such as shear box test or triaxial shear test. However, we cannot design the foundation considering these data as the ground conditions will change once the loads are applied to the soil as there are some soil particles with angularity or sharp edges will break. Once they will break, soil conditions will not remain the same as they were before since the gradation will change. This work is carried out in order to know the impact soil breakage brings to the soil (granular soil). For this purpose, actual ground conditions were simulated in the laboratory by applying one-dimensional compression to soil particles for about $\mathbf{4 5}$ minutes in a Universal Testing Machine (UTM). Different crushing loads to soil particles were applied and the change in the soil behavior was monitored. It was found that due to particle breakage of soil, the engineering properties of sand altered. This research work aims to analyze the effect of particle breakage only in the case of sand.
\end{abstract}

Keywords-shear strength; permeability; shear box test; bearing capacity; crushing load

\section{INTRODUCTION}

Granular soils like sand get crushed when subjected to heavy loading conditions. These materials are commonly used in the compacted sub-grade of flexible or rigid pavements, embankments, dam foundations and other structures [1]. Different granular materials in foundation engineering have different compositions, water content, unit weight, particle size distribution, etc. [2]. When granular materials are subjected to heavy loadings, the particles of soil get crushed and particle breakage occurs [3]. Particle breakage of granular material can occur at different stress levels for different materials $[5,6]$. It can occur due to heavy load on soil caused by pile driving, highway embankments, offshore structures, etc. [4]. Once particle breakage occurs, the soil conditions alter as the gradation of soil changes. Particle breakage occurs when highly loaded particles crush into smaller pieces. We know soil properties are associated with particle size, so a change of properties would occur as a result of soil particles' breaking. A few soil particles may break immediately upon load application, while others may break after a very long time. It is important to know the changes occurring in the geotechnical properties as the soil is subjected to loading for very long time. A precaution must be taken into consideration before the construction of structures is carried out. The geotechnical properties may include particle size distribution (PSD), specific gravity, density, void ratio, shear strength etc. PSD of soil has major effects on the design of earth fill dams and embankments [7-9]. A granular soil material has a particle size ranging from $0.001 \mathrm{~mm}$ to $1000 \mathrm{~mm}$ like granular sand [10]. After crushing, when the particle size distribution is changing, changes may occur in permeability, shear strength, deformation and other granular soil properties [11]. This research work aims to determine the changes that will occur on the engineering properties of sand when it is subjected to crushing under different loading conditions.

\section{PROBLEM STATEMENT}

For structure design the consideration of particle breakage is important. The success of a project doesn't rely upon designing the foundation on laboratorial or in-situ test data. There must be a margin kept for the consideration of particle breakage as the soil is supposed to sustain the desired load for very long and with the passage of time different particles will break due to which soil properties change. Thus there is a need of determining the effects of particle breakage on engineering 
properties of sand due to crushing of its particles at different loading conditions. In this work, the granular sand passing from a $4.75 \mathrm{~mm}$ sieve and retaining on $0.075 \mathrm{~mm}$ sieve was crushed at $5 \mathrm{MPa}, 10 \mathrm{MPa}, 15 \mathrm{MPa}$ and $20 \mathrm{MPa}$ one-dimensional loads in a UTM Machine.

\section{RESEARCH METHODOLOGY}

To simulate the actual conditions of ground (that is when a structure transmits a load onto the soil) in the laboratory we used a special mould known as "pressure mould" in which we kept sand and applied compressive forces with the help of the UTM to break the soil particles. The soil was crushed at different loads (5MPa, $10 \mathrm{MPa}, 15 \mathrm{MPa}$ and $20 \mathrm{MPa})$ and for each state of the soil, tests were performed in the same conditions to analyze the effect of particle breakage in to the geotechnical soil properties.

\section{A. Material Properties}

\section{1) Grain-Size Distribution}

The sizes of soil grains and their distribution vary greatly [12-15]. The grain-size distribution of coarse-grained soil is generally determined by sieve analysis. For a fine grained soil, the grain-size distribution can be obtained by hydrometer analysis.

\section{2) Sieve Analysis}

Sieve analysis is conducted by taking a measured amount of dry, well-pulverized soil and passing it through a stack of progressively finer sieves with a pan at bottom. The amount of soil retained on each sieve was measured, and the cumulative percentage of soil passing through each sieve was determined.

\section{3) Relative Density}

In granular soils, the degree of compaction in the field can be measured according to the relative density, given as:

$$
\mathrm{D}_{\mathrm{r}}=\frac{\mathrm{emax}-\mathrm{e}}{\mathrm{emax}-\mathrm{emin}} \times 100
$$

where emax $=$ void ratio in soil in loosest state, emin $=$ void ratio in soil in densest state, and $\mathrm{e}=$ in situ void ratio.

The relative density of soil can also be expressed in terms of dry unit weight or:

$$
\mathrm{D}_{\mathrm{r}}=\left\{\frac{\mathrm{rd}-\mathrm{rdmin}}{\mathrm{rdmax}-\mathrm{rdmin}}\right\} * \frac{\mathrm{rdmax}}{\mathrm{rd}} \times 100
$$

where $\mathrm{rd}=$ in situ dry unit weight, $r d m a x=d r y$ unit weight in densest state corresponding to emin, and rdmin=dry unit weight in loosest state corresponding to emax.

\section{4) Hydraulic Conductivity}

The voids between soil grains allow water to flow through them. Knowledge of this procedure is required in order to design earth dams, determine the quantity of seepage under hydraulic structures and dewater foundations before and during their construction [16]. The following equation for calculating the velocity of flow of water through a soil was proposed in 1856:

$$
\mathrm{v}=\mathrm{ki}
$$

where $\mathrm{v}=$ Darcy velocity, $\mathrm{k}=$ hydraulic conductivity, $\mathrm{i}=$ hydraulic gradient $=\mathrm{dh} / \mathrm{L}$.

\section{5) Shear Strength}

Soils are essentially frictional materials. They are comprised of individual particles that can slide and roll relative to one another. In the discipline of soil mechanics, it is generally assumed that the particles are not cemented. One consequence of their frictional nature is that the strength depends on the effective stresses in the soil. As the effective stress increases with depth, so in general will the strength [17]. Shear strength of the soil is the internal resistance per unit area that the soil mass offers to resist failure and sliding along any plane inside it. Mohr in 1900 proposed these failure criteria. The limiting shear stress that may be applied to any plane in the soil mass is found to be given by an equation of the form:

$$
\tau=\mathrm{c}+\sigma_{\mathrm{n}} \tan \phi
$$

where $\mathrm{c}=$ cohesion and $\phi=$ friction angle.

Since this research was limited to sand only, so we will not discuss other geotechnical parameters such as Atterberg limits and soil consolidation.

\section{B. Experimental Procedure}

\section{1) Sample Preparation}

The followed procedure to prepare a sand sample from the bulk of soil having a mixed variety of different soils is given below. We knew that the sand has maximum particle size of $4.75 \mathrm{~mm}$ and minimum particle size of $0.075 \mathrm{~mm}$, so the first step was to sieve the soil from a No. 4 sieve, to remove all gravel and larger particles. The second step was to wash the soil sample through a No. 200 wash sieve $(0.075 \mathrm{~mm}$ aperture), to remove all the silt and clay particles. Washing of the soil should be carried out in small quantities until the water passed from the sieve is clean and clear of any particles. The soil (consisting of sand only) was then dried out by placing in the oven for 24 hours (or it may be dried out by the hot plate procedure discussed later). The dried sample should be kept in a safe place so that dust particles would not mix with it. For this research, $200 \mathrm{Kg}$ of pure sand were prepared. The sieves used for sample preparation are shown in Figure 1.
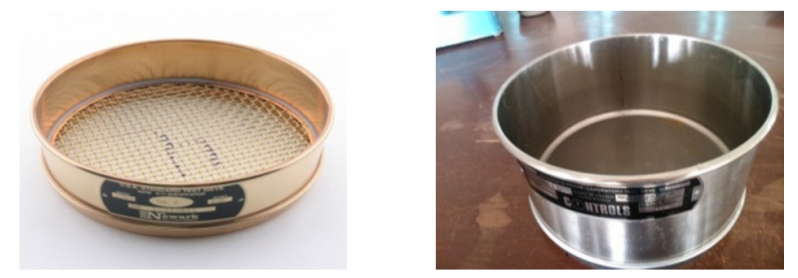

Fig. 1. No. 4 sieve and No. 200 washing sieve

\section{2) Crushing of Sand Samples}

The sand particles were crushed by applying loads of $5 \mathrm{MPa}, 10 \mathrm{MPa}, 15 \mathrm{MPa}$, and $20 \mathrm{MPa}$ for 45 minutes. For the crushing of soil particles, a special mould was used (pressure mould) consisting of a base plate onto which a circular metallic ring $(15 \mathrm{~cm}$ diameter, and $15 \mathrm{~cm}$ height) opened from both sides is placed, and a loading rim which was placed on top of the 
mould system containing the soil to be crushed. The soil was limited by the quantity determined using another cylindrical container (with a capacity of $3.27 \mathrm{Kg}$ ). The soil was then transferred to the mould arrangement and then a loading rim was placed. Once the mould setup was prepared, it was placed in the UTM as shown in Figure 2. For this research work $30 \mathrm{Kg}$ of crushed soil at each loading was obtained. Each loading intensity was applied on the soil for 45 minutes. Then, the soil was removed and the mould was refilled by fresh uncrushed soil and the same loading conditions were applied. The procedure was repeated until we got the required amount of crushed soil for each load The uncrushed soil was crushed by applying the same procedure at $5 \mathrm{MPa} 10 \mathrm{MPa}, 15 \mathrm{MPa}$ and $20 \mathrm{MPa}$.

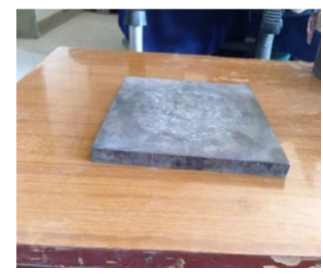

(a)

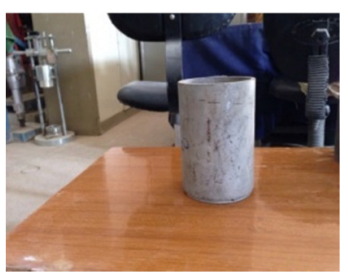

(c)

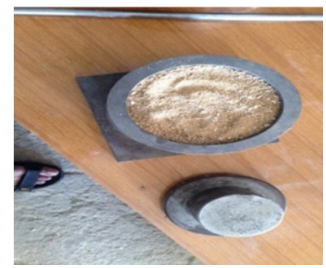

(e)

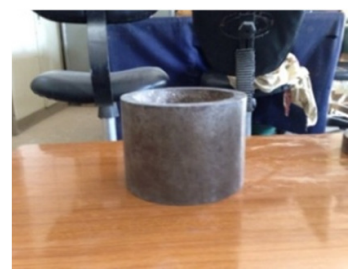

(b)

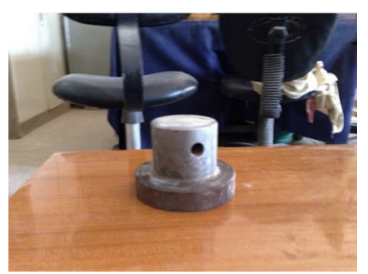

(d)

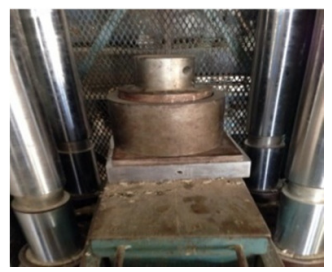

(f)
Fig. 2. Different components of the pressure mould placed in the UTM: (a) Base plate, (b) pressure mould, (c) cylinderical container, (d) loading rim, (e) pressure mould filled with sand, and (f) pressure mould placed in UTM

\section{RESULTS AND DISCUSSION}

\section{A. PSD}

The PSD of sand crushed at $5 \mathrm{MPa}, 10 \mathrm{MPa}, 15 \mathrm{MPa}$ and $20 \mathrm{MPa}$ loads was calculated separately. Merging all the particle size distribution curves at each loading conditions we observe that the percentage of finer soil is increased in the upper sieves as the crushing load is increased. This applies to bottom sieves also, but the effect is not that much as smaller particles are very difficult to break as shown in Figure 3.

\section{B. Specific Gravity or Density}

It was observed that due to crushing the minimum and maximum dry density of particles was reduced. As the crushing of particles is increased by the application of more load, the density of soil particle is further reduced as shown in Table I.

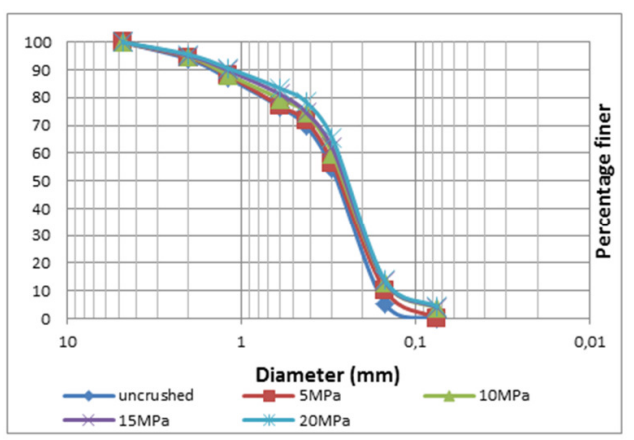

Fig. 3. Effect on the PSD curve due to crushing of sand

TABLE I. EFFECT ON SAND DENSITY

\begin{tabular}{|c|c|c|c|c|}
\hline S.No & Soil condition & $\boldsymbol{\rho}_{\text {dmin }}$ & $\boldsymbol{\rho}_{\text {dmax }}$ & $\boldsymbol{\rho}_{\text {davg }}$ \\
\hline 1 & Uncrushed & 1.59 & 1.88 & 1.735 \\
\hline 2 & Crushed at $5 \mathrm{MPa}$ & 1.57 & 1.87 & 1.72 \\
\hline 3 & Crushed at $10 \mathrm{MPa}$ & 1.56 & 1.85 & 1.705 \\
\hline 4 & Crushed at $15 \mathrm{MPa}$ & 1.54 & 1.83 & 1.685 \\
\hline 5 & Crushed at $20 \mathrm{MPa}$ & 1.51 & 1.81 & 1.66 \\
\hline
\end{tabular}

\section{C. e-K Curve}

We can see that the soil permeability $(\mathrm{K})$ is reducing as the particle crushing is increasing by increasing the crushing load. Also, we can see that for the same voids ratio (e) in each soil condition, we get different permeability values (Figures 4-5).

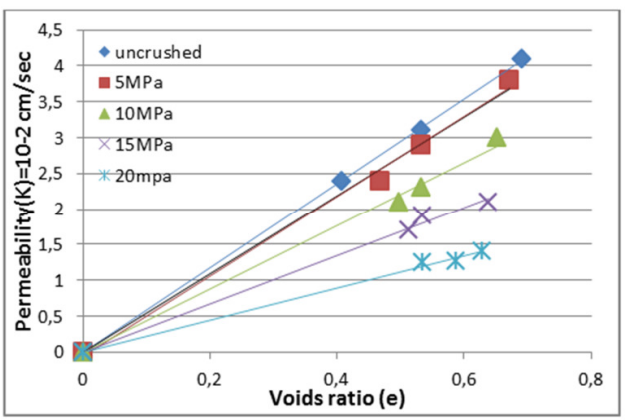

Fig. 4. e-K curve of soil in different states (crushed and uncrushed)

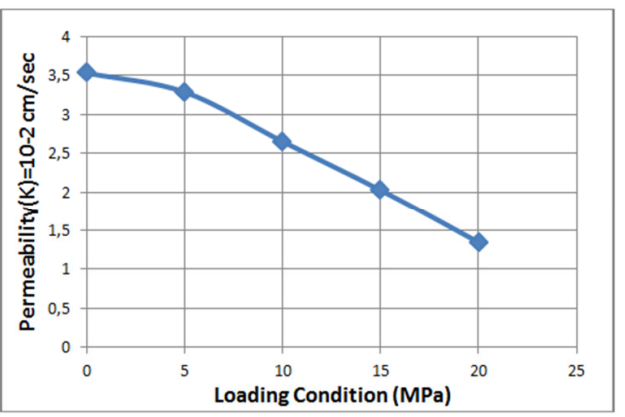

Fig. 5. Effect on the permeability of soil due to crushing at $\mathrm{e}=0.6$ 


\section{Shear Strength}

The shear strength of soil in all conditions (crushed and uncrushed) was determined by applying a normal load of $8.5 \mathrm{Kg}$ and $10.5 \mathrm{KG}$. The weight of the soil was taken as $102 \mathrm{gm}$ in each case. The results are shown in Figures 6-10.

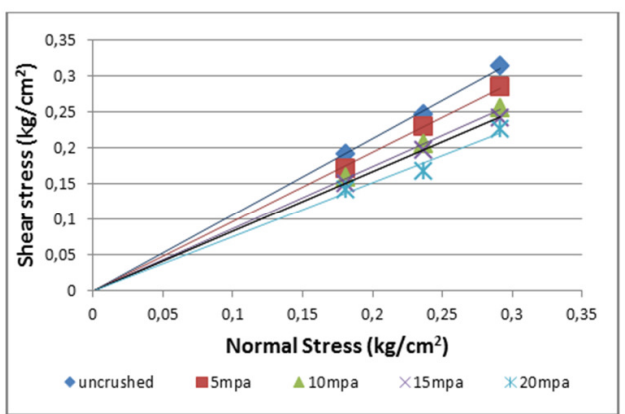

Fig. 6. Effect on the shear envelop of the soil due to crushing

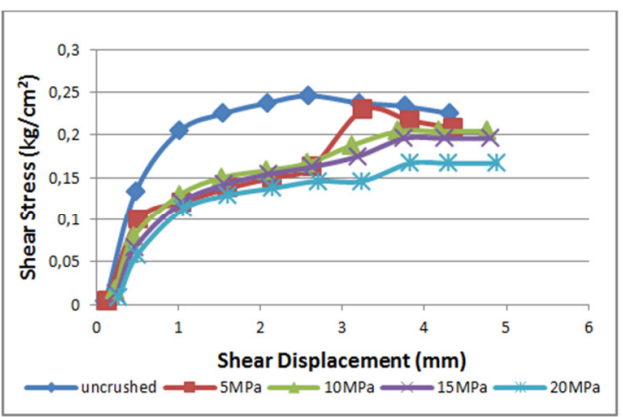

Fig. 7. Shear displacement vs.shear stress under normal load of $8.5 \mathrm{Kg}$

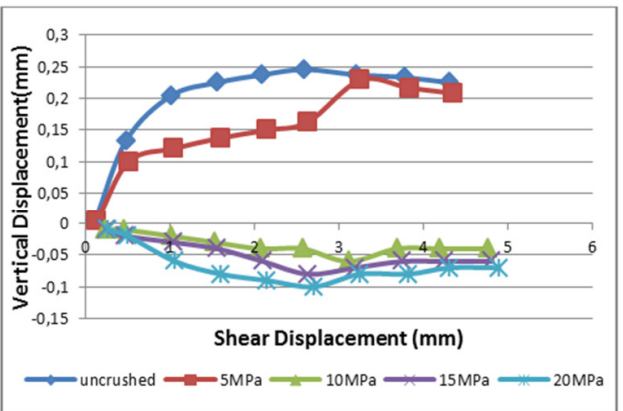

Fig. 8. Shear displacement vs. vertical displacement under normal load of $8.5 \mathrm{Kg}$

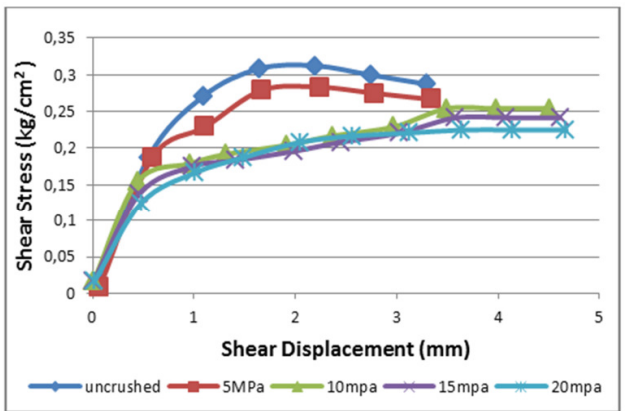

Fig. 9. Shear displacement vs. shear stress under normal load of $10.5 \mathrm{Kg}$

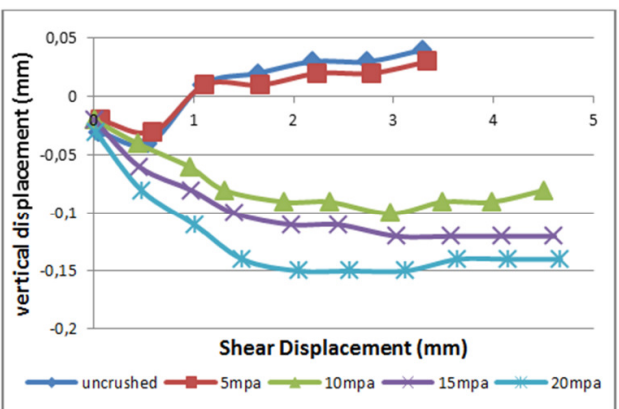

Fig. 10. Shear displacement vs. vertical displacement under normal load of $10.5 \mathrm{Kg}$

\section{CONCLUSION}

Crushing of particles did bring changes in the geotechnical properties of soil. The following conclusions can be made from this research work:

- The gradation (PSD) of soil changed. Increase in crushing load on soil particles increases the percentage of finer particles from various sieves, especially the ones with larger aperture size increased.

- Specific gravity of particles was reduced as the particle breakage increased by applying a greater crushing load. Also, the maximum and minimum dry density of soil reduced as the crushing load kept on increasing.

- The permeability of particles also reduced when the crushing load increased. Even when the voids ratio stayed the same, the permeability of soil, either in crushed or in uncrushed state, was different, and kept reducing as the crushing load was increasing.

- Shear box test results revealed details about the changes occurring in the sand due to crushing. It was observed that dense sand behaved like loose sand as particle breakage was induced.

Thus, some precautionary measures must be taken while designing the foundations of a structure, as the original properties of soil will change once the structure is built and the particles will break due to structural load. Precautionary measures might be taken in the form of considering a significant reduction in the friction angle of soil while designing the foundation as the structure will transfer load onto the soil for very long time thus inducing significant particle breakage. Or we may apply greater factor of safety in determining the safe bearing capacity of the soil, as the bearing capacity of the soil is determined by considering shear parameters.

\section{REFERENCES}

[1] L. E. Vallejo, Z. Chik, "The evolution of crushing in granular materials and its effect on their mechanical Properties", Proceedings of the 16th International Conference on Soil Mechanics and Geotechnical Engineering, Millpress Science Publishers/IOS Press, 2006

[2] M. L. Chen, G. W. Jian, B. Gan, W. H. Jiang, J. W. Zhou, "Physical and Compaction Properties of Granular Materials with Artificial Grading behind the Particle Size Distributions", Advances in Materials Science and Engineering, Vol. 2018, pp. 1-20, 2018 
[3] O. H. Al Hattamleh, H. H. Al-Deeky, M. N. Akhtar, "The Consequence of Particle Crushing in Engineering Properties of Granular Materials", International Journal of Geosciences, Vol. 4, No. 7, pp. 1055-1060, 2013

[4] T. A. Rousan, O. Al Hattamleh, R. A. Dwairi, "Effect of Inherent Anisotropy on Shear Strength Following Crushing of Natural Aqaba Subgrade Sand", Jordan Journal of Civil Engineering, Vol. 5, No. 3, pp. 431-445, 2011

[5] J. P. Hyslip, L. E. Vallejo, "Fractal analysis of the roughness and size distribution of granular materials", Engineering Geology, Vol. 48, No. 3 4, pp. 231-244, 1997

[6] J. Yang, X. D. Luo, "Exploring the relationship between critical state and particle shape for granular materials", Journal of the Mechanics and Physics of Solids, Vol. 84, pp. 196-213, 2015

[7] B. B. Mandelbrot, The Fractal Geometry of Nature, W. H. Freeman and Company, 1983

[8] J. J. Wang, D. Zhao, Y. Liang, H. B. Wen, "Angle of repose of landslide debris deposits induced by 2008 Sichuan Earthquake”, Engineering Geology, Vol. 156, pp. 103-110, 2013

[9] M. Rieu, G. Sposito, "Fractal Fragmentation, Soil Porosity, and Soil Water Properties: I. Theory", Soil Science Society ofAmerica Journal, Vol. 55, No. 5, pp. 1231-1238, 1991

[10] Z. Y. Ma, F. N. Dang, H. J. Liao, "Numerical study of the dynamic compaction of gravel soil ground using the discrete element", Granular Matter, Vol. 16, No. 6, pp. 881-889, 2014

[11] G. Lumay, N. Vandewalle, "Compaction of anisotropic granular materials: experiments and simulations", Physical Review E, Vol. 70, No. 5,2004

[12] M. A. Martin, M. Reyes, F. J. Taguas, “An entropy like parameter of particle size distributions as packing density index in complex granular media", Granular Matter, Vol. 19, No. 1, p. 9, 2017

[13] W. Choi, Y. Son, J. Park, S. Noh, T. Bong, "An In-vestigation on Crushing and Particle Size Distribution Characterizes of Bottom Ash as Compaction Energy", 2013 World of Coal Ash (WOCA) Conference, Lexington, USA, April 22-25, 2013

[14] H. Shahnazari, R. Rezvani, "Effective Parameters for the Particle Breakage of Calcareous Sands: An Experi- mental Study", Engineering Geology, Vol. 159, pp. 98-105, 2013

[15] M. S. Lim, D. C. Wijeyesekera, A. Zainorabidin, I. Bakar, "The Effects of Particle Morphology (Shape and Sizes) Characteristics on its Engineering Behaviour and Sustainable Engineering Performance of Sand", International Journal of Integrated Engineering, Vol. 4, No. 4, pp. 27-37, 2012

[16] M. A. Martin, M. Reyes, F. J. Taguas, "Estimating soil bulk density with information metrics of soil texture", Geoderma, Vol. 287, pp. 66-70, 2017

[17] F. Casini, G. M. Viggiani, S. M. Springman, "Breakage of an artificial crushable material under loading", Granular Matter, Vol. 15, No. 5, pp. 661-673, 2013 